\title{
VIBRATIONAL SPECTRA OF $\mathrm{HgMoO}_{4}$ AND $\mathrm{HgWO}_{4}$
}

\author{
G. BLASSE \\ Physical Laboratory, State University, Sorbonnelaan 4, Utrecht, Netherlands
}

(Received 4 March 1974)

\begin{abstract}
The i.r. and Raman spectra of mercury molybdate and tungstate $\left(\mathrm{HgMoO}_{4}\right.$ and $\left.\mathrm{HgWO}_{4}\right)$ are reported. They can be interpreted assuming an effectively tetrahedral $\mathrm{Mo}(\mathrm{W})$ coordination, although the crystallographic coordination is sixfold (with two long distances). The same model seems to work for the tungstates with wolframite structures, e.g. $\mathrm{CdWO}_{4}$.
\end{abstract}

\section{INTRODUCTION}

THE CRYSTAL structure of the isomorphous compounds $\mathrm{HgMoO}_{4}$ and $\mathrm{HgWO}_{4}$ has been reported recently[1]. In the course of our studies on the vibrational and electronic spectra of mixed metal oxides containing highly-charged transition-metal ions (like $\mathrm{Nb}^{5+}, \mathrm{W}^{6+}$ ) it seemed interesting to study these compounds in more detail for two reasons. In the first place the octahedral coordination of $\mathrm{Mo}(\mathrm{W})$ in $\mathrm{HgMo}(\mathrm{W}) \mathrm{O}_{4}$ is very irregular with two long $\mathrm{Mo}(\mathrm{W})-\mathrm{O}$ distances. In the second place the mercury ions with a linear twocoordination by oxygen might influence the properties of the molybdate or tungstate group in an unexpected way. In this paper the vibrational spectra of $\mathrm{HgMoO}_{4}$ and $\mathrm{HgWO}_{4}$ are reported. Their luminescent properties will be discussed elsewhere using the present results.

\section{EXPERIMENTAL}

Samples were prepared by firing an intimate mixture of $\mathrm{HgO}$ and $\mathrm{MoO}_{3}$ or $\mathrm{WO}_{3}$ at $600^{\circ} \mathrm{C}$ using a 50 per cent excess of $\mathrm{HgO}$. The reaction products were near-white. They were checked by $X$-ray analysis using $\mathrm{CuK} \alpha$ radiation. The vibrational spectra were measured at room temperature. Raman spectra were obtained using a Spectra Physics 700 Raman spectrometer with an argon ion laser (courtesy Dr. J. H. van der Maas of this University). I.R. spectra were measured in $\mathrm{KBr}$ and CsI pellets and in paraffin using a Hitachi EPI-G3 grating spectrometer (down to $400 \mathrm{~cm}^{-1}$ ) and a Grubb Parsons DM4 spectrometer with a CsI prism (down to $200 \mathrm{~cm}^{-1}$ ). Samples of $\mathrm{MgWO}_{4}, \mathrm{ZnWO}_{4}$ and $\mathrm{CdWO}_{4}$ were prepared by usual ceramic techniques with firing temperatures between 1100 and $1200^{\circ} \mathrm{C}$.

\section{RESULTS}

In Table 1 the vibrational spectra of $\mathrm{HgMoO}_{4}$ and $\mathrm{HgWO}_{4}$ are tabulated. In Table 3 we have given the same data for $\mathrm{CdWO}_{4}$. Results for $\mathrm{MgWO}_{4}$ and $\mathrm{ZnWO}_{4}$ are similar to those for $\mathrm{CdWO}_{4}$. Our i.r. spectra of $\mathrm{MgWO}_{4}$ and $\mathrm{ZnWO}_{4}$ differ in some details
Table 1. Vibrational spectra of $\mathrm{HgMoO}_{4}$ and $\mathrm{HgWO}_{4}$

\begin{tabular}{ccll}
\hline \multicolumn{2}{c}{$\mathrm{HgMoO}_{4}$} & \multicolumn{2}{c}{$\mathrm{HgWO}_{4}$} \\
I.R. & Raman & I.R. & Raman \\
\hline $890(\mathrm{~s})$ & $912(\mathrm{~s})$ & $915(\mathrm{~m})$ & $930(\mathrm{~s})$ \\
$\sim 860(\mathrm{~m})$ & $855(\mathrm{~m})$ & $880(\mathrm{~s})$ & $850(\mathrm{~m})$ \\
$820(\mathrm{w})$ & $825(\mathrm{~m})$ & $855(\mathrm{~m}, \mathrm{sh})$ & $815(\mathrm{~m})$ \\
$665(\mathrm{~s})$ & $694(\mathrm{~m})$ & $660(\mathrm{br})$ & $705(\mathrm{br})$ \\
$\sim 620(\mathrm{w}, \mathrm{sh})$ & $\sim 670(\mathrm{w}, \mathrm{sh})$ & & \\
$540(\mathrm{~m})$ & $522(\mathrm{~m})$ & $535(\mathrm{~m})$ & $540(\mathrm{~m})$ \\
$490(\mathrm{~m})$ & $500(\mathrm{w})$ & $490(\mathrm{~m})$ & $515(\mathrm{w})$ \\
$365(\mathrm{w})$ & $377(\mathrm{~m})$ & $380(\mathrm{w})$ & $380(\mathrm{~m})$ \\
$335(\mathrm{~m})$ & $345(\mathrm{w})$ & $330(\mathrm{~m})$ & $335(\mathrm{w})$ \\
$320(\mathrm{~s})$ & $315(\mathrm{~m})$ & $315(\mathrm{~s})$ & $300(\mathrm{~m})$ \\
$305(\mathrm{~s})$ & $290(\mathrm{w})$ & $300(\mathrm{~s})$ & $285(\mathrm{~m})$ \\
$270(\mathrm{~m})$ & $270(\mathrm{~m})$ & $285(\mathrm{w})$ & $235(\mathrm{w})$ \\
$220(\mathrm{w})$ & $220(\mathrm{~s})$ & $250(\mathrm{~m})$ & $200(\mathrm{~s})$ \\
\hline
\end{tabular}

All values in $\mathrm{cm}^{-1}$. Abbreviations-s: strong, $\mathrm{m}$ : medium, w: weak, sh: shoulder, br: broad.

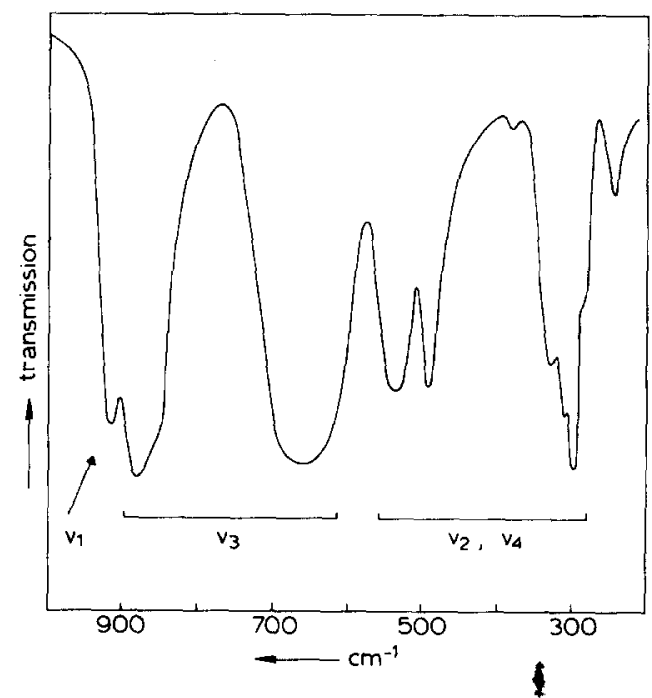

Fig. 1. Infrared spectram of $\mathrm{HgWO}_{4}$. 


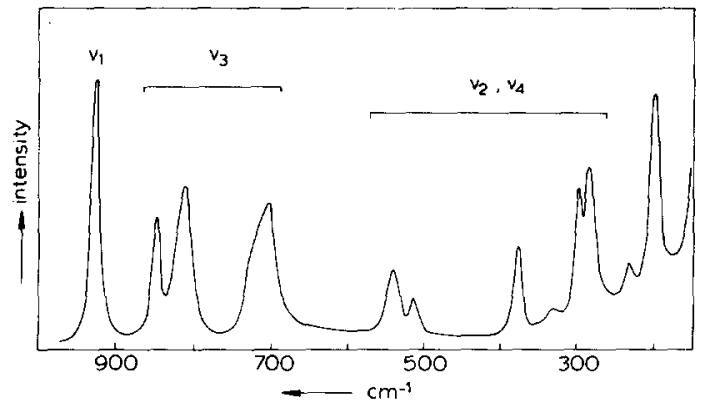

Fig. 2. Raman spectrum of $\mathrm{HgWO}_{4}$.

from those given by Clark and Doyle[2], our i.r. spectrum of $\mathrm{CdWO}_{4}$ equals the spectrum given by Nyquist and Kagel[3]. Figures 1 and 2 present the vibrational spectra of $\mathrm{HgWO}_{4}$.

\section{DISCUSSION}

As in previous papers we will try to assign the observed bands to the tungstate or molybdate internals. At first sight this seems to be a rather complicated problem, since the structure consists of edge-sharing tungstate (molybdate) octahedra, which would involve the absence of isolated molecular groups. The six Mo-O distances, however, are strongly different, viz. $1.722 \AA(2 x), 1.944 \AA(2 x)$ and $2.228 \AA(2 x)[1]$. In view of this we tried to analyse the vibrational spectra by considering the crystal structure as a packing of $\mathrm{Mo}(\mathrm{W}) \mathrm{O}_{4}$ groups and $\mathrm{Hg}^{2+}$ ions, i.e. we only consider the four nearest oxygen ions to belong to the molecular $\mathrm{Mo}(\mathrm{W}) \mathrm{O}_{4}$ group. These groups do not have oxygen ions in common. The site symmetry of these groups is $C_{2}$ and there are two such groups per primitive unit cell. The space group symmetry is $C_{2 h}(C 2 / c)$. For such a configuration the number of internals to be expected can be derived easily as indicated in Table 2 .

First we note that the exclusion principle to be obeyed under $C_{2 h}$ symmetry is observed experimentally (Table 1). This, by the way, does not depend on our simplified structure consideration. The predictions of Table 2 are nicely realized by the experimental

Table 2. Correlation diagram for the vibrational modes of $\mathrm{HgMoO}_{4}$ and $\mathrm{HgWO}_{4}$ assuming tetrahedral $\mathrm{Mo}(\mathrm{W}) \mathrm{O}_{4}$ groups with site symmetry $C_{2}$

\begin{tabular}{|c|c|c|}
\hline$T_{d}$ symmetry $^{a}$ & Site symmetry $C_{2}{ }^{b}$ & $\begin{array}{l}\text { Two groups under } \\
C_{2 h} \text { space group } \\
\text { symmetry }\end{array}$ \\
\hline $\begin{array}{ll}v_{1} & A_{1}(\mathrm{R}) \\
v_{2} & E(\mathbf{R}) \\
v_{3}, v_{4} & T_{2}(\text { i.r., R) }\end{array}$ & $\begin{array}{l}A \\
2 A \\
\left\{\begin{array}{l}A \\
2 B\end{array}\right.\end{array}$ & $\begin{array}{c}A_{\mathrm{g}}+A_{u} \\
2 A_{g}+2 A_{u} \\
A_{g}+A_{u} \\
2 B_{g}+2 B_{u}\end{array}$ \\
\hline
\end{tabular}

${ }^{a}(R)$ : Raman-active, (i.r.): i.r.-active. ${ }^{b}$ No selection rules.

${ }^{c} g$ modes Raman-active, $u$ modes i.r-active.
Table 3. Vibrational spectra of $\mathrm{CdWO}_{4}$

\begin{tabular}{cl}
\hline I.R. & Raman \\
\hline $875(\mathrm{~m})$ & $900(\mathrm{~s})$ \\
$805(\mathrm{~s})$ & $775(\mathrm{~m})$ \\
$\sim 680(\mathrm{~m}, \mathrm{sh})$ & $710(\mathrm{w})$ \\
$600(\mathrm{~s})$ & $690(\mathrm{w})$ \\
$510(\mathrm{~m})$ & $550(\mathrm{~m})$ \\
$445(\mathrm{~m})$ & $520(\mathrm{w})$ \\
$405(\mathrm{w})$ & $390(\mathrm{~m})$ \\
$350(\mathrm{w})$ & $355(\mathrm{w})$ \\
$320(\mathrm{~s}, \mathrm{br})$ & $310(\mathrm{~m})$ \\
$270(\mathrm{w})$ & $272(\mathrm{w})$ \\
$230(\mathrm{~m})$ & $235(\mathrm{w})$ \\
& $180(\mathrm{w})$ \\
\hline
\end{tabular}

results of Table 1. The strong line in the Raman spectrum of $\mathrm{HgWO}_{4}$ at $930 \mathrm{~cm}^{-1}$ is assigned to the $A_{g}$ component of $v_{1}$. Its $A_{\mu}$ component is found in the i.r. spectrum at $915 \mathrm{~cm}^{-1}$. Note that the value for $v_{1}$ in the case of $\mathrm{HgWO}_{4}$ is very close to values observed normally for the tetrahedral tungstate group. A comparison is given in Table 4, where values are given for $\mathrm{Na}_{2} \mathrm{WO}_{4}$ with $\mathrm{WO}_{4}$ groups in the spinel structure [4] and $\mathrm{CaWO}_{4}$ and $\mathrm{BaWO}_{4}$ with $\mathrm{WO}_{4}$ groups in the scheelite structure[5]. For the octahedral tungstate group the $v_{1}$ mode is situated some hundred wavenumbers lower as is substantiated by the value for the $\mathrm{WO}_{6}$ group in $\mathrm{Ba}_{2} \mathrm{CaWO}_{6}$ with ordered perovskite structure[6]. Note that the value of $v_{1}$ is not largely influenced by the way in which the octahedra are condensed (corner-, edge- or face-sharing)[7]. The position of the $v_{1}$ mode in $\mathrm{HgWO}_{4}$ and $\mathrm{HgMoO}_{4}$ is in our opinion strong evidence for the structural simplification proposed.

For the asymmetric stretching mode $v_{3}$ we expect three components in the Raman as well as in the i.r. spectrum. This is observed experimentally, e.g. 850 , 815 and $705 \mathrm{~cm}^{-1}$ in the i.r. and 880,855 and $660 \mathrm{~cm}^{-1}$ in the Raman spectrum of $\mathrm{HgWO}_{4}$. It should be realized, however, that the lower-frequency band of these three seems to contain another band (see Fig. 1). In the case of $\mathrm{HgMoO}_{4}$ this is not the case, but there is a weak extra band present in this frequency range. This might be due either to a second harmonic or combination band or to the incompleteness of our structural description.

In the lower frequency range down to $250 \mathrm{~cm}^{-1}$ we find always five bands of at least medium intensity in both spectra for both compounds. These are assigned to the expected five components of the $v_{2}$ and $v_{4}$ modes. Bands at still lower energies are then due to external vibrations.

It is interesting to compare the averaged values for the $v_{3}$ mode in the case of $\mathrm{HgWO}_{4}$ with similar results for other tungstates (see Table 4). For molybdates the situation is analogous. We see that the values for $\mathrm{HgWO}_{4}$ are only slightly lower than for $\mathrm{Na}_{2} \mathrm{WO}_{4}$, $\mathrm{BaWO}_{4}$ and $\mathrm{CaWO}_{4}$ with tungstate tetrahedra and 
Table 4. Comparison of the averaged value of $v_{1}$ and $v_{3}$ for several tungstates

\begin{tabular}{llccccc}
\hline \multicolumn{1}{c}{ Compound } & Crystal structure & Raman & I.R. & Raman & I.R. & References \\
\hline $\mathrm{HgWO}_{4}$ & $\mathrm{HgWO}_{4}$ & 930 & 915 & 785 & $\sim 790$ & this work \\
$\mathrm{MgWO}_{4}$ & wolframite & 925 & 910 & 740 & 730 & this work \\
$\mathrm{ZnWO}_{4}$ & wolframite & 915 & 880 & 730 & 700 & this work \\
$\mathrm{CdWO}_{4}$ & wolframite & 900 & 875 & 725 & 695 & this work \\
$\mathrm{Na}_{2} \mathrm{WO}_{4}$ & spinel & 930 & - & 814 & 840 & 4 \\
$\mathrm{BaWO}_{4}$ & scheelite & 922 & - & $\simeq 805$ & 828 & 5 \\
$\mathrm{CaWO}_{4}$ & scheelite & 910 & - & $\simeq 810$ & 813 & 5 \\
$\mathrm{Ba}_{2} \mathrm{CaWO}$ & ordered perovskite & 818 & - & - & 620 & 6 \\
\hline
\end{tabular}

All values in $\mathrm{cm}^{-1}$

very much higher than for $\mathrm{Ba}_{2} \mathrm{CaWO}_{6}$ with tungstate octahedra. The latter comparison, however, is not fair, since the $v_{3}$ mode shifts to higher frequencies upon edge sharing $[7,8]$.

We, therefore, conclude that the vibrational spectra of $\mathrm{HgMo}(\mathrm{W}) \mathrm{O}_{4}$ can be analyzed satisfactorily by assuming tetrahedral $\mathrm{Mo}(\mathrm{W}) \mathrm{O}_{4}$ groups in the crystal structure, although the $\mathrm{Mo}^{6+}\left(\mathrm{W}^{6+}\right)$ ion is formally coordinated by six oxygen anions. This is also substantiated by e.g. the Mo-O distances. The ionic radii for four- and six-coordinated $\mathrm{Mo}^{6+}$ and threecoordinated $\mathrm{O}^{2-}$ are $0.42,0.60$ and $1.36 \AA$, respectively [9]. The average of the six $\mathrm{Mo}-\mathrm{O}$ distances in $\mathrm{HgMoO}_{4}$ $(1.965 \AA)$ agrees with the distance calculated for sixcoordinated $\mathrm{Mo}^{6+}(1.96 \AA)$. The average of the four shorter $\mathrm{Mo}-\mathrm{O}$ distances in $\mathrm{HgMoO}_{4}(1.833 \AA)$ is only a little longer than the distance calculated for fourcoordinated $\mathrm{Mo}^{6+}(1.78 \AA)$.

It is realized that this assignment may be less appropriate due to the occurrence of extensive mixing of internal vibrations, since many of them have the same symmetry species. Furthermore $\mathrm{HgO}$ shows strong i.r. absorption up to $600 \mathrm{~cm}^{-1}$ [3]. The structure of $\mathrm{HgO}$ contains $\mathrm{Hg}-\mathrm{O}$ chains with linearly coordinated $\mathrm{Hg}(\mathrm{Hg}-\mathrm{O}$ distance $2.03 \AA)[10]$. In HgMo$(\mathrm{W}) \mathrm{O}_{4}$ the $\mathrm{Hg}^{2+}$ ion is also linearly coordinated with $\mathrm{Hg}-\mathrm{O}$ distances equal to $2.03 \AA$, so that it is not excluded that the lower-frequency stretching vibrations contain considerable $\mathrm{Hg}-\mathrm{O}$ character.

Finally we wish to report that similar considerations are also valid for the tungstate wolframites. Of these we studied $\mathrm{MgWO}_{4}, \mathrm{ZnWO}_{4}$ and $\mathrm{CdWO}_{4}$. Usually the structure of these compounds is considered to contain zig-zag chains of edge-sharing octahedra. Two of the six W-O distances are, however, much longer than the other four. For the isomorphous $\mathrm{NiWO}_{4}$ the following values have been found: $1.79 \AA(4 x)$ and $2 \cdot 19 \AA(2 x)[11]$. Although the space group $(P 2 / c)$ is different from that of $\mathrm{HgMo}(\mathrm{W}) \mathrm{O}_{4}$, the relevant symmetries are the same as in the case of the mercury compounds. As a consequence Table 2 predicts also the number of bands to be expected for the wolframites containing $\mathrm{W}^{6+}$ ions. A comparison between Table 2 and Table 3, where we have given our experimental results for $\mathrm{CdWO}_{4}$, shows a satisfactory agreement. The strong Raman line at $900 \mathrm{~cm}^{-1}$ is the $A_{g}$ com- ponent of $v_{1}$, whereas the i.r. spectrum shows the $A_{\mu}$ component at $875 \mathrm{~cm}^{-1}$. The three components of the $v_{3}$ mode are found at 775,710 and $690 \mathrm{~cm}^{-1}$ in the Raman and at 805,680 and $600 \mathrm{~cm}^{-1}$ in the i.r. spectrum. The $v_{2}$ and $v_{4}$ modes are found in the lowerfrequency range.

These results are also given in Table 4. The position of $v_{1}$ clearly points to an effectively tetrahedral coordination. The average values of $v_{3}$ are lower than the values observed for the tungstate tetrahedron and also for $\mathrm{HgWO}_{4}$. This may be an indication that the simplification of effectively tetrahedral coordination of $\mathrm{W}^{6+}\left(\mathrm{Mo}^{6+}\right)$ is more justified for the mercury compounds than for the tungstates with wolframite structure.

In a forthcoming paper we will show that the luminescence properties of these mercury compounds can also be described starting from a tetrahedral coordination and that the correlation between the luminescence of tungstates (molybdates) can be described in this way.

Acknowledgement-The author is greatly indebted to $\mathrm{Mr}$. G. P. M. van den Heuvel for the preparation of the samples and the performance of the i.r. measurements.

\section{REFERENCES}

1. W. Jeitschko and A. W. Sleight, Acta crystallogr. B29, 869 (1973).

2. G. M. Clark and W. P. Doyle, Spectrochim. Acta 22, 1441 (1966)

3. R. A. Nyquist and R. O. Kagel, Infrared Spectra of Inorganic Compounds. Academic Press, New York (1971).

4. J. Preudhomme and P. Tarte, Spectrochim. Acta 28A, 69 (1972).

5. P. Tarte and M. Liegeois-Duyckaerts, Spectrochim. Acta 28A, 2029 (1972) and M. Liegeois-Duykaerts and P. Tarte, ibid, 28A, 2037 (1972).

6. A. F. Corsmit, H. E. Hoefdraad and G. Blasse, J. inorg. nucl. Chem. 34, 3401 (1972).

7. G. Blasse and G. P. M. van den Heuvel, Z. phys. Chem. 84, 114 (1973).

8. P. Tarte, Spectrochim. Acta 18, 467 (1962).

9. R. D. Shannon and C. T. Prewitt, Acta crystallogr. B25, 925 (1969).

10. K. Aurivillius, Acta crystallogr. 9, 685 (1956).

11. R. O. Keeling, Acta crystallogr. 10, 209 (1957). 